\title{
NARRACIONES Y METÁFORAS EN LA CONSTRUCCIÓN DEL PENSAMIENTO CIENTÍFICO Y LA EPISTEMOLOGÍA EDUCATIVA
}

\author{
Narratives and metaphors in the construction \\ of scientific thought and educational epistemology
}

\section{Narrations et métaphores dans la construction de la pensée scientifique et l'epistémologie éducative}

Juan Carlos González Faraco* y Anita Gramigna**

* Universidad de Huelva. Facultad de Ciencias de la Educación. Departamento de Educación. Campus de El Carmen. 21997 Huelva. Correo-e: farazo@ubu.es

** Università degli studi di Ferrara. Facoltà di lettere e Filosofia. Dipartimento di Scienze Umane (Area Pedagogica). Via savonarola, 27. 44100 Ferrara, Italia. Correo-e: anita.gramigna@unife.it

Fecha de recepción: marzo de 2009

Fecha de aceptación definitiva: julio de 2009

Biblid [(1130-3743) 21, 2, 2009, 79-94]

RESUMEN

En este artículo se pretende reflexionar, desde una perspectiva epistemológica, sobre las conexiones y espacios de intersección entre la formación del pensamiento científico y la teoría educativa. Para ello se recurre, sólo como punto de partida, o como referencia básica pero no única, a la epistemología de Gregory Bateson, pues sus aportaciones al estudio de la educación, aunque indirectas, pueden ser muy sugestivas en este empeño. El núcleo argumental del artículo gira en torno a tres consideraciones fundamentales. Una, que el pensamiento es siempre narrativo. Dos, que para la construcción del saber científico en general, como de la educación 
en particular, resulta sumamente provechoso adquirir una buena competencia epistemológica referida al pensamiento narrativo. Y, como consecuencia, que es muy importante desarrollar un amplio espectro semántico en las metáforas de las narraciones científicas, singularmente las que conciernen a la educación.

Palabras clave: epistemología educativa, Bateson, pensamiento científico, complejidad, pensamiento narrativo.

\section{SUMMARY}

In this article we reflect epistemologically upon the connections and spaces of intersection between the formation of scientific thought and educational theory. To accomplish this we resort, only as a point of departure or as a basic but not unique reference, to the epistemology of Gregory Bateson, given that his contributions to the study of education, albeit indirect, can be very suggestive. The nucleus of the argument of this article revolves around three fundamental considerations. First, that thought, all types of thought, is always narrative, which is to say that it uses metaphors to explain phenomena. Second, that for the construction of scientific thought in general, and educational thought in particular, it is exceedingly useful to acquire good epistemological competency with reference to narrative thought. And, finally, as a result, it is very important to develop an ample semantic spectrum in the metaphors of scientific narratives, especially in those that concern education.

Key words: educational epistemology, Bateson, scientific thought, complexity, narrative thought.

\section{SOMMAIRE}

Dans cet article, on veut réfléchir, d'un point de vue épistémologique, sur les connexions et les espaces d'intersection entre la formation de la pensée scientifique et la théorie de l'éducation. Comme point de départ et comme référence basique mais non unique, on recourt à l'épistémologie de Gregory Bateson, puisque ses apports à l'étude de l'éducation, bien que des allusions, peuvent être très suggestives à cet égard. Le noyau de l'argument de l'article tourne autour de trois considérations fondamentales. L'une, que la pensée est toujours narrative. Deux, pour la construction du savoir scientifique en général, comme de l'éducation en particulier, semble extrêmement profitable acquérir une bonne compétence épistémologique rapportée à la pensée narrative. Et en conséquence, c'est très important de développer un ample spectre sémantique dans les métaphores des narrations scientifiques, singulièrement celles qui concernent à l'éducation.

Mots clés: épistémologie éducative, Bateson, pensée scientifique, complexité, pensée narrative. 
Lo bello y lo feo, lo literal y lo metafórico, lo sano y lo enfermo, lo cómico y lo serio..., incluso el amor y el odio, son temas que hoy la ciencia evita.

G. Bateson, Angels Fear, 1987

\section{Pero Qué cosa es una idea: a modo de introducción}

Este artículo parte de la consideración de que el pensamiento, cualquier tipo de pensamiento, incluido el pensamiento científico relativo a las ciencias llamadas exactas y experimentales, es siempre narrativo, lo que implica que se vale de metáforas para explicar los fenómenos. Los lenguajes, códigos e instrumentos de la ciencia se estructuran según lógicas específicas que podemos denominar gramáticas. ¿Qué es, pues, lo que diferencia el modo de proceder de la ciencia del de la literatura? No es arriesgado afirmar que el pensamiento científico, muy a menudo, no reconoce como tales ni las metáforas ni las gramáticas que emplea, organiza y crea. Suele ser un pensamiento que se ocupa más de la explicación que de la comprensión de los fenómenos, y que, habitualmente, utiliza ciertos modelos -que a su vez se estructuran en torno a datos- cuya descripción esencial intenta abarcar los elementos estructurales de un fenómeno, y no su "fenomenología compleja". Cabría decir, a modo de ejemplo y parafraseando a Gregory Bateson ${ }^{1}$, que la explicación científica es al fenómeno como el mapa es al paisaje. No cabe duda de que para orientarnos es indispensable un mapa, pero no es menos cierto que la complejidad y la mudanza del paisaje superan a cualquier mapa. El error, en consecuencia, no reside en el hecho de servirse de un mapa, sino más bien en creer que el mapa es el paisaje.

¿Qué tiene que ver este razonamiento con los procedimientos y los lenguajes de las ciencias experimentales? ¿Estamos, incluso en este ámbito, ante narraciones que podrían beneficiarse de un más amplio espectro semántico y, por tanto, de una más profunda conciencia de las potencialidades metafóricas de sus lenguajes? Escribe Bateson (1993, 257):

1. Gregory Bateson (1904-1980) fue un eminente científico e intelectual, acaso menos conocido de lo que debiera en nuestros círculos académicos y, singularmente, en los pedagógicos. Estudió historia natural en Cambridge, pero muy pronto abandonó esta disciplina para dedicarse a la antropología. Fue discípulo de Malinowski y de Radcliffe-Brown y trabajó con Margaret Mead, con quien estuvo casado. Posteriormente, contribuyó, junto a otros grandes investigadores, al nacimiento y desarrollo de la cibernética. Bateson también se ocupó del estudio de cuestiones psiquiátricas y psicoterapéuticas y, por último, se volcó en estudios biológicos sobre la comunicación en los animales. En los últimos años de su vida, impartió en el Kresge College de California un curso titulado "Ecología de la mente", que sería también el título de la obra que le daría mayor fama: Steps to an Ecology of the Mind (1972), en la que queda de manifiesto la variedad de sus intereses científicos y el carácter unitario y holístico de su perspectiva epistemológica. 
El experimento es un método de torturar a la naturaleza para obtener una respuesta desde el punto de vista de nuestra propia epistemología, no atendiendo a una epistemología ya inmanente en la naturaleza [...]. En lo que se refiere a la cuantificación será siempre un artificio para evitar la percepción de la pauta. Y la postura clínica será siempre un medio de evitar esa apertura de la mente o de la percepción que pueda poner ante nosotros la totalidad de las circunstancias que rodean el fenómeno que queremos investigar. Por supuesto, a los clínicos les interesa la etiología y establecer las causas por las que los pacientes han llegado a estar en el estado en que se hallan. Pero yo estoy interesado en algo mucho más amplio. Estoy interesado en lo que es una idea. Y en qué ideas y qué pauta de ideas han intervenido para hacer que los pacientes hayan llegado al estado en que hoy están.

Estamos convencidos de que puede ser sumamente interesante y fértil reflexionar sobre la formación del pensamiento científico y, específicamente, del pensamiento educativo a la luz de la epistemología batesoniana, aunque no en solitario sino con el concurso de otras fuentes intelectuales, como la que representa, por ejemplo, el pensamiento complejo. La razón fundamental es que Gregory Bateson fue un eminente y singular hombre de ciencia que fundió, primero en su intensa experiencia vital y luego en sus teorías, la visión tecno-científica con la estético-humanística. A lo cual hay que añadir su condición de verdadero maestro.

En Bateson ${ }^{2}$ podemos encontrar ideas -muchas o pocas, mejores o peores-, pero sobre todo podemos encontrar actitudes, que entiendo son tan necesarias como las primeras. Hay en él, junto al ideal del científico, el ideal de maestro.

\section{CIENCIA, COMPLEJIDAD Y NARRACIÓN}

Recuperemos el hilo de nuestro argumento y volvamos a la metáfora y a su función epistémica. La metáfora ofrece un modelo de comprensión que capta algunos rasgos esenciales del fenómeno, pero no lo agota. A diferencia de la explicación "prosaica", por llamarla de alguna manera, a diferencia de cualquier paráfrasis, la metáfora pone a disposición de nuestro pensamiento y de su actividad organizativa un amplio espectro semántico, una considerable gama de significados a los que puede acceder estableciendo nexos epistemológicos y conexiones lógicas inéditas o no previstas en el pensamiento prosaico de la explicación.

Como dice Bateson (1993, 244), "la lógica clásica es una pobre simulación de la causa". Y lo es porque simplifica. La realidad, sin embargo, es compleja y, como ella, lo son también los fenómenos, pues se ven condicionados por una especie

2. Aguirre Romero $(2008,7)$. 
de danza relacional, cambiante y evolutiva, en la que los factores que interactúan son legibles desde diferentes planos. En este sentido trascienden la explicación, pues ésta sólo puede alcanzar algunos aspectos, incluso algunos que pudieran ser esenciales. En consecuencia, las narrativas implicadas en la explicación de los fenómenos deberían abarcar un espectro semántico plural, mostrarse abiertas a la diferencia y al hospedaje de otras narraciones, de otros instrumentos culturales, intelectuales y lingüísticos que las enriquezcan. Esto es, deben abrirse al más extenso abanico semántico que las metáforas implicadas puedan producir.

Mas como la metáfora describe algo al mismo tiempo que alude a ese algo, explica y deja intuir, representa sin ser exhaustiva y es más eficaz cuando, en la descripción que elabora, deja mayores márgenes de posibilidad a cuanto rehúye la explicación o la previsión. Así pues, su pauta de evocación de la realidad servirá de algo en la medida en que sea capaz de amparar lo imprevisto, es decir, de recuperar el equilibro ante el dinamismo del fenómeno mismo, de reconfigurarse al entrar en contacto con las contingencias, con la especificidad de la experiencia, en una palabra: con todas las posibles variables que los fenómenos nos presentan, incluso guardando fidelidad a la estructura funcional que los sostiene.

Parafraseando una feliz expresión de Bachelard (1975) a propósito del método científico, cabe afirmar que el mejor método científico -y por consiguiente el pensamiento sobre el que se asienta- es el que es capaz de aprender de la realidad que interpreta y describe, el que se reconstituye ante su ineludible transformación, ante la danza relacional que enlaza el fenómeno estudiado con el ecosistema, entendiendo de este modo como una unidad de sentido la relación interactiva y cambiante que une al sujeto con su medio. El sistema se conforma por un organismo que, encarado con la naturaleza, participa en el juego entre mutación y estabilidad, entre innovación y diferenciación.

La medicina, por poner un ejemplo de ciencia clásica, se dedica con sus narraciones justamente a esto, a estudiar los circuitos y los contextos dentro de los cuales este juego puede causar una patología (McMichael, 2001). Necesita, por ello, de un lenguaje de amplio espectro narrativo. Las variables, los ámbitos, los circuitos y sus infinitas combinaciones son el fruto, inevitablemente complejo, al que nos ha conducido la evolución biológica. A partir de estas consideraciones, las enseñanzas de T. Khun (2006) en torno a la transitoriedad de los paradigmas científicos y a la historicidad de los modelos que representan, resultan aún más sugestivas, sobre todo a la hora de valorar la posibilidad de recuperar viejas narraciones -tradiciones, costumbres, saberes- en el marco de nuevas gramáticas.

En suma, una buena competencia narrativa puede ayudarnos a confrontar las diferentes representaciones del fenómeno estudiado. Sería así posible lograr un sugerente encuentro de interpretaciones que puede reunir a un tiempo la riqueza de la subjetividad y la precisión de la objetividad científica. La cuestión se vuelve relevante en un doble sentido: como método para indagar y elaborar hipótesis, y como encrucijada o hábitat común de comunicación entre competencias, profesionalidades, tradiciones y vivencias diferentes. 
Por otra parte, es innegable que el extraordinario progreso de la investigación científica deja grandes agujeros de insatisfacción (Jonas, 2002; Husserl, 1999). El pensamiento narrativo nos podría ayudar no a sustituir la impronta tecnocrática o tecnocientificista de la ciencia, pero sí a llenar algunas de sus lagunas, proporcionándonos otros puntos de vista y propiciando una valiosa operación de análisis crítico y clarificación epistemológica, volviendo más rico y fructífero el diálogo entre las diversas perspectivas, competencias, códigos y formas de pensamiento.

Creemos que el conocimiento también ha de nutrirse de la estética ${ }^{3}$, valerse de la metáfora y tener en cuenta lo inopinado, cualidad esencial de un pensamiento verdaderamente complejo y elemento clave de su gran potencialidad educativa (Morin, 2000, 2007; Morin, Ciurana y Motta, 2003; Velilla, 2002). El conocimiento necesita, pues, de una mirada narrativa (en el amplio sentido con que la hemos venido entendiendo), una mirada plural en los contenidos, en los modelos, en las perspectivas, en los procedimientos, en los lenguajes; una mirada que sepa albergar la diferencia, lo extraordinario, lo exótico; una mirada, en suma, que se haga eco de lo múltiple en el sujeto, en las culturas, en las ciencias. En este mismo sentido, la mitología, la meditación, así como tantos y tantos saberes atávicos de culturas que tachamos de minoritarias y poco evolucionadas, pueden representar fuentes preciosas para la investigación científica, el bienestar social y el desarrollo humano, y, desde luego, para mejorar la educación (Santos Rego, 2001; De Sousa Santos, 2005) ${ }^{4}$. A propósito de la construcción narrativa de la realidad y desde un punto de vista precisamente educativo, J. Bruner (1997, 168) escribía estas elocuentes palabras:

Dedicamos una cantidad enorme de esfuerzo pedagógico a enseñar los métodos de la ciencia y el pensamiento racional: lo que supone la verificación, lo que constituye la contradicción, cómo convertir simples afirmaciones en proposiciones comprobables y demás siguiendo la lista. Pues éstos son los métodos ${ }^{5}$ para crear una realidad según la ciencia. Sin embargo, vivimos la mayor parte de nuestras vidas en un mundo construido según las normas y los mecanismos de la narración.

3. En el pensamiento de Bateson la estética representa el estudio de los procesos a través de los que se crea y se reconoce la belleza.

4. A este respecto resulta especialmente iluminadora la obra del sociólogo portugués Boaventura de Sousa Santos, y en concreto su "Sociología de las ausencias". Vale igualmente la pena evocar su concepto de "zona de contacto" en el marco de su revisión crítica de la racionalidad moderna. Esta "zona" se nutre, de un lado, de una "zona epistemológica", en la que se confrontan la ciencia moderna y el saber ordinario, y, de otro, de una "zona colonial" que opone a colonizador y colonizado. Boaventura de Sousa rechaza esta visión dicotómica, que naturalmente genera jerarquía, desigualdad y no reconoce la diferencia. Y establece, de este modo, su crítica a la que denomina "razón indolente", frente a la que propone como alternativa una "razón cosmopolita" que daría cabida a aquellos grupos culturales y saberes tradicionalmente marginados y silenciados, mediante la creación de nuevos espacios de "traducción intercultural".

5. Expresiones subrayadas en el original por el propio autor. 
Seguro que la acción podría aportar oportunidades más valiosas de las que aporta para crear la sensibilidad metacognitiva que se necesita para enfrentarse al mundo de la realidad narrativa y sus afirmaciones alternativas.

En sintonía con las ideas de Bruner, pensamos que puede ser muy útil para el saber científico y sus prácticas profundizar en la conciencia de la condición narrativa de sus lenguajes, lo que a su vez favorecería el multialfabetismo y aumentaría la capacidad de elaborar mapas cognitivos complejos. Mapas preparados para reconfigurarse al compás de los procesos, en lugar de empeñarse en determinar o hacer cristalizar los fenómenos. Por otro lado, podría contribuir a ese esfuerzo de concientización epistemológica que nos puede esclarecer la estructura de nuestro discurso y arrojar luz sobre las preguntas y problemas que tendemos a olvidar o arrinconar. Hablamos, en suma, de un pensamiento científico que puede trabajar simultáneamente en planos distintos a los de las clásicas orientaciones cuantitativa y cualitativa, un binomio metodológico notoriamente manido e insuficiente. Hablamos, en consecuencia, de una especie de dialéctica entre las narraciones de un saber basado "en la evidencia" y narraciones de un saber basado "en el relato", entre abstracción y complejidad fenomenológica.

Valga el siguiente listado de proposiciones como recuento de los nodos o intersecciones fundamentales de nuestro argumento y de sus consecuencias:

- Todo el pensamiento, incluido el que consideramos científico y experimental, se vale de narraciones.

- Con alguna frecuencia la ciencia, que se ha desarrollado tanto en la dirección tecnológica, no es sin embargo suficientemente consciente de la naturaleza narrativa de sus procedimientos y sus textos.

- Este problema tiene evidentes consecuencias para la praxis, dado que la estructura y la naturaleza del discurso condicionan los procedimientos científicos, determinan su heurística y anudan las preguntas que nos hacemos con las respuestas que buscamos. En el caso de la medicina, por seguir con el ejemplo elegido anteriormente, la anamnesis, el diagnóstico y la prognosis tienen mucho que ver con tales preguntas y tales respuestas.

- Es sumamente necesaria una competencia epistemológica madura y, singularmente, una epistemología del pensamiento narrativo a la hora de afrontar los problemas: de ahí la importancia de disponer de un amplio espectro semántico en las metáforas empleadas por las narraciones científicas.

- La complejidad fenomenológica de la subjetividad puede servirse de esa competencia para con ella plantar cara a los límites de la simplicidad -O reduccionismo abstracto- de la objetividad, sin que ello impida aprovechar sus explicaciones.

Naturalmente, es necesario desarrollar y desentrañar estos "nodos", que acabamos de apuntar, a la luz de una epistemología, de una "toma de partido" que explicitaremos 
en los siguientes apartados y que concierne a ciertas ideas cardinales, con evidentes repercusiones para la teoría educativa: la condición sistémica del sujeto, la centralidad de las premisas de las que no tenemos conciencia, y el gran alcance práctico de la epistemología y la ontología de la relación.

\section{El CONOCIMIENTO DEL ÁRBOL: PREMISAS EPISTEMOLÓGICAS Y ÉTICAS}

Como ya hemos dicho, la base crítica inicial de nuestras reflexiones procede de la epistemología batesoniana, un planteamiento que, atravesando la Teoría de la cognición de Palo Alto, personificada sobre todo por Maturana y Varela (Maturana y Varela, 1980, 1987; Capra, 1996), nos conduce a los textos de Morin, en los que es extensamente argumentada en relación con sus consecuencias educativas. En esta confluencia teórica se inserta nuestra argumentación y es muy importante mostrar desde un principio sus cartas, puesto que, como nos advierte Bateson, la estructura epistemológica de nuestra reflexión determina las cuestiones que nos planteamos y los procedimientos que seguimos para encontrar las respuestas, para construir la solución de los problemas y para elaborar nuevas ideas ${ }^{6}$. Determina, por ende, los puntos de vista y condiciona sus narraciones. Para un mejor conocimiento del árbol se necesita tanto el mito como la botánica, advierte Bateson (Bateson y Bateson, 1994). El conocimiento $-\mathrm{y}$, por ello, la ciencia- no guarda relación sólo con el acreditado reino de la racionalidad o de la norma regular y previsible (Manghi, 2004). No por casualidad ya en el siglo XVIII G. Vico hablaba, en su Scienza nuova, de una "sabiduría poética" independiente de la reflexión o, lo que es lo mismo, separada de la razón entendida como intelecto. Una sabiduría fuente de emociones intensas, pero a la par creadora de "imágenes de verdad", en referencia a los "universales fantásticos" que han sabido aprehender los caracteres típicos, los signos que fundamentan los fenómenos, el mundo y la misma vida en su fabuloso despliegue.

Insistimos que el conocimiento, cualquier tipo de conocimiento, necesita de la estética, de ese saber sensible que nos permite percibir la estructura relacional en el interior de un fenómeno, entre los mismos fenómenos y entre ellos y el sistema al que pertenecen. Por todo ello, y no nos cansaremos de reiterarlo, el conocimiento necesita de la tensión metacognitiva de la metáfora y no puede desdeñar lo inesperado o lo improbable. El conocimiento del mito, para Bateson,

6. En la "nueva" Historia de la Educación, deudora del giro cultural y lingüístico que ha venido operándose en las ciencias sociales, muchos autores ponen de relieve la trascendencia de los "sistemas de razón" (vale decir, epistemologías) a partir de las cuales se construyen los textos históricos, se establecen los problemas y se conjeturan también las soluciones. "El lenguaje -escribe NóvoA (2001, 52) - no puede verse únicamente como una rúbrica teórica. Necesita ser tomado como un texto que redefine las subjetividades e identidades, que adscribe reglas y comportamientos, que configura significados y convicciones". 
participa del mismo proceso mental que dio y da origen a la ciencia. Más aún, las metáforas de las que está entretejida la mitología pueden representar una especie de "Correctivos" para nuestros errores lingüísticos y epistemológicos7; en suma, para esa deriva de la ciencia y de la tecnología que, según Bateson, ha conformado el saber occidental en base a una alarmante carencia de sabiduría sistémica.

Parece, pues, muy oportuno y también atractivo indagar en torno al pensamiento narrativo y a su posible aportación al saber científico. Y poner sobre la mesa la trama especulativa que puede contribuir a clarificar los procesos a través de los cuales puede construirse tal heurística, teniendo bien presente que los niveles y métodos de la investigación están condicionados por las opiniones sólo en parte conscientes -con más frecuencia de lo que imaginamos- que el científico alberga en relación con el tipo de fenómeno que estudia. Nuestra reflexión surge de la exigencia de poner en evidencia, siempre que sea posible, las ideas implícitas y las premisas de nuestra mirada, de nuestra búsqueda, pues el resultado de nuestro trabajo tendrá mucho que ver con esas ideas y esas premisas. "¿Qué pensar si: lo que podemos percibir de nuestro sí mismo es nuestra propia metáfora; y somos nuestra propia epistemología; y nuestro mundo interior es esa epistemología, nuestro microcosmos, y nuestro microcosmos es una metáfora apropiada del macrocosmos?", se preguntaba Bateson (1993, 298).

La naturaleza, en efecto, procede mediante metáforas. A juicio de Bateson (1993, 299), la historia natural viene a ser una historia macrocósmica, con la que guardan una relación armónica todas las pequeñas historias naturales, de modo que la comprensión de una pequeña abre el camino a la comprensión de la grande (Bateson, 1993, 299). Siguiendo esta lógica, cada organismo viene a ser, en cierto modo, un reflejo microcósmico de una matriz total (la naturaleza), que cabe entender como red de ideas, o sea, como una epistemología, y específicamente como una epistemología recursiva y, al mismo tiempo, como una epistemología de la recursividad. Bateson elige como símbolo epistemológico de lo recursivo al Ouroboros, la mítica serpiente que se muerde la cola, evocación del círculo que no tiene principio ni fin. "Estoy seguro -escribe $(1993,257)$ - de que si uno se educa en el mundo en el cual el pensamiento es preponderantemente lineal (y todos nos hemos educado en ese mundo), uno comprueba que resulta extraordinariamente difícil ver las vueltas del Ouroboros". Y por si quedaba alguna duda, concluye: "En el pensamiento occidental (quizás en todo el pensamiento humano) existe una

7. De nuevo aquí no se entiende este término, al menos no se entiende exactamente, según la versión más acreditada en el debate pedagógico, es decir, como ciencia que verifica y afina el estatuto del conocimiento (instrumentos, ámbitos, lenguajes, métodos) (Sola, 2002). Se entiende en el sentido, más lato, que le da Bateson, quien concibe la epistemología como la combinación de un sector de las ciencias naturales (que estudia cómo conocen los organismos y sus agregaciones) con la filosofía (que se ocupa del problema de los límites y características de los procesos cognoscitivos) (Bateson, 1990; Manghi, 2004; Pulvirenti, 2004). Para acercarnos al debate más contemporáneo podemos recurrir una vez más a Morin (1988). 
fuerte tendencia a pensar y a hablar como si el mundo estuviera hecho de partes separables" (Bateson, 1993, 292).

Son muchos los que han puesto y siguen poniendo de relieve cómo el saber científico occidental, tal como se ha venido conformando a lo largo de los siglos, ha primado una perspectiva de tipo cuantitativo -con datos y estadísticas traducibles en cifras- y una mirada lineal, proclive a descubrir la normatividad y con ella la previsibilidad de los fenómenos (Parini, 2006; Panikkar, 2006; Russell, 2005; Colom, 2003). Pero si bien es cierto que el lenguaje científico es narrativo, que se vale de metáforas y que se organiza mediante una gramática aquilatada con la que estructura sus discursos, no es menos cierto que exhibe otra diferencia con el lenguaje poético o literario, o artístico en general, y es que sus narraciones han privilegiado las cosas en lugar de las relaciones. De ahí la marcada preeminencia de lo cuantitativo sobre lo cualitativo, y de la linealidad frente a otros modos de organización cognitiva.

Siguiendo esta óptica, otro posible error de la ciencia occidental radica en su carácter dicotómico, que le hace separar lo intelectual de lo emocional, al sujeto de la sociedad y a la humanidad de la naturaleza (Galimberti, 1999). Ello se debe a la sobrevaloración de la consciencia, que sólo puede reconocer una pequeña información de la mente, según una finalidad que el científico define como instrumental. La consciencia, que es tan sólo un sector del vasto sistema individuosociedad-ecosistema, no es apta para percibir tal enjambre de conexiones, y cae en el error y en la petulancia de reivindicar exclusivamente para sí el carácter de mente. La finalidad consciente es simplificadora, se preocupa sólo de encontrar el camino más corto para alcanzar su propio fin. Actuando de esa guisa, acaba por ignorar la condición sistémica del mundo, creyendo tener el control de un sistema del que no es más que una parte pequeña.

Siempre que el sistema es ignorado en beneficio de la finalidad se generan daños. La finalidad consciente ha hecho que, desde Darwin en adelante, la unidad de significado en el contexto de la selección natural anide en el individuo aislado, en la familia o en la especie singular, en oposición a otras sociedades, razas o especies. De ahí el prejuicio según el cual el hombre es señor y patrón de una naturaleza de la que disfruta o transforma, según ciertas finalidades conscientes y al socaire de una racionalidad instrumental, dicotómica e hiperespecializada.

Bateson contrapone a este planteamiento la ecología de las ideas, o sea, la reflexión sobre las relaciones entre el hombre y el sistema en que vive, sobre la red que conecta a todos los seres vivos al medio y lleva inscritas las huellas evolutivas de sus orígenes. Es una formulación teórica que aspira a alcanzar la sabiduría sistémica, el conocimiento del sistema cibernético. Para lograrlo es imprescindible volver a reunir lo que ha sido arbitrariamente separado: la consciencia con lo inconsciente y la mente individual con la más vasta mente del ecosistema. Son numerosos los medios para conseguir este anudamiento y atañen a las actividades humanas en las que se ponen en funcionamiento todas las dimensiones de la mente: el arte en sus variadas expresiones, la religión, la música, la relación con 
la naturaleza, el amor. En esta concepción la unidad de supervivencia es el individuo en su medio.

Todo ello representa el fundamento teórico que nos sirve de referencia para una reflexión cuya hipótesis medular es ésta: la etapa cultural en la que vivimos ha exasperado la tendencia presistémica, determinista y tecnocrática que acompaña a la ciencia moderna desde su origen, lo que se manifiesta en la fragmentación superespecializada de un saber que siempre se somete a un único modelo de pensamiento o de ciencia (Mèlich, 2006, 2008). Un modelo que no reconoce la condición narrativa de sus lenguajes y que, en consecuencia, tiende a metabolizar la tensión transformadora de las diferencias en la univocidad de un solo lenguaje. La ciencia, como acaece con muchos de los campos de la vida civil en Occidente, se ve cada vez más sometida al imperio de la economía. Se trata de una ciencia que, en general, produce tecnología para responder de manera atomística a problemas globales que, sorprendentemente, son pensados como locales o singulares, es decir, como meros "síntomas", por retomar de nuevo el lenguaje de la ciencia médica.

La autonomía del individuo va siendo concebida, cada vez más, como un asunto del mercado y, en consecuencia, como ámbito propicio para la producción y desarrollo comercial de cierto tipo de productos y bienes que, no pocas veces, se presentan como alternativos a los que proporciona el saber científico "ortodoxo", por ejemplo, la medicina. Despunta así una primera y seria contradicción entre un modelo existencial, social y relacional marcado por el consumismo genuino de la ideología neoliberal, y un incontenible aluvión de preguntas-respuestas que claman por un mayor bienestar y una mejor educación. Por desgracia, todo parece indicar que se está produciendo un aparatoso proceso de conversión de esa proliferación contaminada de conocimientos en una diversidad de productos listos para ser vendidos.

Por otra parte, resiste con vigor y mantiene su predominio la concepción galileana de una ciencia que crea separaciones (el modelo gnoseológico clásico, para entendernos) en perjuicio de una visión holística (Santos Rego, 2001; Corbellini, 2003). La persistencia de esta epistemología tácita, unida a la capacidad estructuradora de las conductas, de la vida social y el conocimiento que posee la ideología de mercado, ha potenciado, y hasta qué punto, las estrategias y procesos de estandarización y la parcelación de las competencias, y ha estimulado notablemente la negación de lo subjetivo, de lo cualitativo y de lo emocional. Tal abstracción congela primeramente el factor de diferencia, pluralidad y alteridad en el proceso de construcción del saber científico y sus lenguajes, dado que posterga y desoye la especificidad del sujeto y sus criterios de juicio. Y por fin elabora narraciones que no son consideradas como tales y que son definidas desde la óptica autorreferencial de la objetividad científica (Pontecorvo, 1993).

Desde el punto de vista de la teoría pedagógica, es evidente que esta concepción condiciona y obstaculiza la germinación del proceso de conocimiento, la colaboración responsable y el saber compartido que harían más pródiga y eficiente cualquier educación. Pero, además, nos ha llevado a un empobrecimiento 
cultural y material que se ha vuelto dramático para muchas poblaciones del tercer mundo y que maniata la dialéctica trans-formadora de confrontación-intercambio de nuestras indagaciones científicas.

\section{Metáfora y METACOGNITIVIDAD EN LA EDUCACióN}

En el contexto de esta argumentación crítica, se concibe la naturaleza como "matriz total", partiendo del proceso por el cual cualquier organismo, transformándose, se convierte a sí mismo en una imagen de la naturaleza, como ya señalamos de la mano de Bateson. La metáfora es una figura retórica en la que una descripción se traslada de un ámbito a otro, que contiene, respecto del primero, uno o más criterios de semejanza. Pero, en este ámbito de significación, la metáfora amplía su significado más habitual al insertarse en un proceso cognoscitivo y comunicativo vinculado, en la secuencia de su desarrollo, a alguna forma de similitud. De este modo, llega a asumir una dimensión estructural del saber, incluso del que se define como "científico" ${ }^{8}$ y hasta matemático. El espesor reflexivo de la metáfora no la oscurece, pues nace justamente de la riqueza y de la pluralidad de su semántica. La multiplicidad de sus significados y de sus sentidos puede, en fin, ayudarnos a construir caminos de significación del mundo.

A este respecto, Bruner hace notar que los científicos han venido recurriendo desde hace mucho tiempo a todo género de intuiciones, argucias y metáforas para tratar de acercar su modelo especulativo a la naturaleza, y también para que la naturaleza se adapte a su modelo, definiendo convenientemente lo que hay que entender por "naturaleza".

El proceso de creación de la ciencia es narrativo. Consiste en hilar hipótesis sobre la naturaleza, comprobarlas, corregir las hipótesis y aclararse las ideas. En ruta hacia la comprobación de hipótesis comprobables, jugamos con las ideas, intentamos crear anomalías, intentamos encontrar formas claras de rompecabezas que podamos aplicar a las problemáticas intratables para que se puedan convertir en problemas solubles, nos inventamos trucos para sortear las ciénagas (Bruner, 1997, 142).

También el aprendizaje de las teorías y nociones científicas necesita nutrirse de las narraciones y sus metáforas. "Propondré -agrega finalmente Bruner (1997, 143) que convirtamos característicamente nuestros esfuerzos de entendimiento científico a la forma narrativa o, digamos, heurísticos narrativos. Nuestros significa tanto de los científicos como de los alumnos que ocupan las aulas en las que enseñamos".

8. La razón de entrecomillar esta palabra se debe a que queremos poner de relieve una vez más que no tiene sentido dividir la "ciencia" en "científica" y "humanística". Tal separación sólo tiene sentido si se usa instrumentalmente para clarificar el discurso y en ningún caso presuponiendo una especie de jerarquía en función de su respectivo grado de calidad. 
Blumenberg (2003), por su parte, considera que logos y mythos son dos formas discursivas dotadas de igual dignidad, llamadas a integrarse para acceder de la mano al conocimiento y a la legibilidad del mundo, pues su diferencia más que lógica es tan sólo morfológica. A no dudarlo, si hubiera que elegir una de las manifestaciones más elocuentes de lo mítico o de lo imaginario en la época moderna, cabría señalar el progreso científico-tecnológico (Carretero, 2003; Steiner, 2007). A la ciencia y a la tecnología se las identifica primordialmente como productos de la investigación, sin caer a veces en la cuenta de que entre éstos, por debajo y acaso por encima de éstos, se hallan también esos mitos que tanto tienen que ver con las epistemologías implícitas de los científicos, de quienes patrocinan sus productos y de quienes los adquieren, es decir, de los clientes de la ciencia. En este hábitat de significación, el desarrollo se vuelve sinónimo de crecimiento regido por la tecnociencia, y ésta llega a valorarse en términos de propiedad intelectual y emblema y canon de la modernización (González Faraco, 2005). Sin embargo, con tan sólo cambiar la definición de ciencia y de tecnología, descubrimos que carece de sentido singularizar lo que es múltiple: que la ciencia y la tecnología no son únicas ni sólo occidentales, que hay diversos modelos en las diferentes culturas y civilizaciones y, por último, que una ciencia o una técnica concreta no nos conducen automáticamente al desarrollo (Shiva, 2008).

En la enseñanza, sea en la escuela primaria o en la universidad, conviene siempre contar con un concepto de conocimiento y de ciencia que contemple, al mismo tiempo, los procesos y sus condicionantes mediante una operación recursiva de contextualización. Tal concepción presupone un pensamiento científico abierto a la complejidad de relaciones y procesos. Exige un pensamiento conectivo y lenguajes solidarios, aptos para descifrar y afrontar los problemas globales que gravitan sobre el presente. Un conocimiento que induce a realizar actos y cogniciones responsables, pues liga la acción al contexto, divisa las secuencias y las reverberaciones de los procesos y perfila una estética relacional.

Nada de ello es posible sin emanciparnos de la fragmentación, de la especialización tranquilizadora, de las aproximaciones unívocas y de los estilos monocordes que la tecnocracia produce. Un saber que adolece de esas "cualidades" ignora la ecología de las acciones humanas, es ciego ante los mitos que él mismo alimenta y resulta incapaz de generar una consciencia epistemológica. No sabe enfrentarse a la transitoriedad de los modelos y a la historicidad de la ciencia, y finalmente esquiva la reflexión ética (Morin, 1984; Habermas, 2003; Chomsky, 2006).

La posibilidad de sobrevivir con dignidad en este planeta, depende de la adquisición de una nueva mente. Esta nueva mente se debe forjar, entre otras cosas, con una epistemología completamente distinta que informará de acciones pertinentes?.

9. VARela $(1992,48)$. 
La perspectiva de investigación sistémica que se denomina "ecología profunda del conocimiento" puede servirnos para profundizar en las grandes posibilidades cognitivas de una educación adherida a la propuesta teórica que venimos esbozando. Las finalidades pedagógicas que hemos sugerido se conjugan plausiblemente con los escenarios de la hermenéutica, pues sólo dentro de un paisaje como el descrito sería posible la convivencia de diferentes paradigmas cognitivos y modos de lectura del mundo.

La experiencia humana y, por tanto, las prácticas relacionadas con la formación, revisten, desde esta óptica, un carácter esencialmente interpretativo que nos incita, en la investigación pedagógica, a un esfuerzo de comprensión, que no de explicación, de los fenómenos. Tal como sostiene Gadamer (1991-1994), el conocimiento existe fuera y más allá de la objetividad del método científico y gnoseológico clásico (Righetti, 2006). Desde un punto de vista educativo, puede decirse que la experiencia es un acontecimiento que trans-forma la consciencia mediante la fusión de horizontes que se produce en el encuentro de experiencias diferentes. Entonces, ganan preeminencia las historias, las tradiciones, los códigos de todas las culturas, sus narraciones, sus mitologías y las prácticas que desencadenan y de las que surgen. La hermenéutica, en esta misma onda, reivindica el valor de los saberes tradicionales, su dignidad gnoseológica, como una forma de rebelión ante un paradigma científico único que encumbra la objetividad, la mensurabilidad y la previsibilidad.

¿Qué significa más concretamente todo ello? Significa que tenemos necesidad de un lenguaje científico que metabolice los conocimientos para ensanchar sus valores, sus ecosistemas, sus instituciones, al amparo de una ecología de sus transformaciones. Se trataría, por supuesto, de una ciencia profundamente ética, pues los lazos que la sostendrían en este proceso debieran ser lazos solidarios, "actes de reliance", que diría Morin. Pues la crisis ética de nuestro tiempo es una crisis a la par de la relación y de la alianza entre el individuo, la sociedad y la especie. Por ello resulta tan inaplazable recuperar las fuentes de la ética, es decir, sus fuentes de responsabilidad y solidaridad, recuperando la "reliance" de la cadena individuo/ comunidad/especie, a través de la específica regeneración de la "reliance" con el otro, con la comunidad, con la sociedad y, al extremo, con la especie humana (Morin, 2006b; Carrizo, 2002).

Si en el curso de la evolución la humanidad ha provocado dinámicas ecológicas que han producido un visible impacto tecnocrático en la sociedad, en la educación y en particular en la escolaridad, igualmente y al mismo tiempo ha creado mitos, ritos y narraciones en torno al sentido de las cosas. Lo que significa que la consciencia del componente metafórico y narrativo de la praxis científica puede inducir y beneficiar la integración de las orientaciones cuantitativa y cualitativa, y científico-natural y científico-humanística (a estas alturas binarismos ya insostenibles), y así encaminarse hacia un saber complejo (Bocchi y Ceruti, 1985, 2004). 
En este marco, puede ser posible salvar y cultivar una ética de las diferencias, premisa insoslayable para una democracia cognitiva planetaria. Y será posible hacerlo si nos abrimos a la pluralidad de lenguajes y perspectivas, sobre la base de una educación integrada e integradora y de un pensamiento conectivo, riguroso y creativo, capacitado para transitar simultáneamente por las diversas formas de la inteligencia que habitan este mundo.

\section{REFERENCIAS BIBLIOGRÁFICAS}

Aguirre Romero, J. M. (2008) Bateson y la complejidad: entre el orden y la diferencia. Espéculo: Revista de Estudios Literarios, 38, 10 pp. Http://www.ucm.es/info/especulo/ numero38/bateson.htlm.

Bachelard, G. (1975) La philosophie du non. París, PUF.

Bateson, G. (1988) Pasos hacia una ecología de la mente. Una aproximación revolucionaria a la autocomprensión del hombre. Buenos Aires, Carlos Lohlé.

- (1990) Espíritu y Naturaleza. Buenos Aires, Amorrortu Ediciones.

- (1993) Una sagrada unidad. Pasos ulteriores hacia una ecología de la mente. Barcelona, Gedisa.

Bateson, G. y Bateson, M. C. (1994) El temor de los ángeles. Epistemología de lo sagrado. Barcelona, Gedisa.

Bateson, M. C. (2004) Como yo los veía: Margaret Mead y Gregory Bateson. Barcelona, Gedisa.

Blumenberg, H. (2003) El trabajo del mito. Barcelona, Paidós.

Bocchi, G. y Ceruti, M. (1985) La sfida della complessità. Milán, Feltrinelli.

- Educazione e globalizzazione. Milán, Raffaello Cortina.

Bruner, J. (1997) La educación, puerta de la cultura. Madrid, Visor.

CAPra, F. (1996) TheWeb of the Life. Nueva York, Doubleday-Anchor Books.

Carretero Pasín, A. E. (2003) La persistencia del mito y lo imaginario en la cultura contemporánea. Politica y Sociedad, 43 (2), 107-126.

Carrizo, L. (2002) Con Edgar Morin: diálogos sobre Ética y Desarrollo. Documento incluido en la Biblioteca Digital de la Iniciativa Interamericana de Capital Social, Ética y Desarrollo, Banco Interamericano de Desarrollo (http://www.iadb.org/etica).

Снomsky, N. (2006) Sobre democracia y educación. Barcelona, Paidós.

Colom, A. J. (2003) La educación en el contexto de la complejidad: la teoría del caos como paradigma educativo. Revista de Educación, 332, 233-248.

Gadamer, H. G. (1991-1994) Verdad y Método (I y II). Salamanca, Sígueme.

Galimberti, U. (1999) Psiche e Tecne. L'uomo nell'età della técnica. Milán, Feltrinelli.

Giap ParinI, E. (2006) Sapere scientifico e modernità. Roma, Carocci.

GonzÁlez Faraco, J. C. (2005) Ideas para repensar el desarrollo como política de conocimiento: un análisis educativo. Alfa. Revista de la Asociación Andaluza de Filosofía, 16, 129-147.

Gramigna, A. (ed.) (2003) Semantica della differenza. Roma, Aracne.

Habermas, J. (2003) La ética del discurso y la cuestión de la verdad. Barcelona, Paidós.

HusserL, H. (1999) La crisis de las ciencias europeas y la fenomenología trascendental. Madrid, Ediciones Altaya.

Jonas, H. (2002) Il principio responsabilità. Un'etica per la civiltà tecnologica. Turín, Einaudi.

Khun, T. S. (2006) La estructura de las revoluciones científicas. Madrid, Fondo de Cultura Económica. 
McMichael, T. (2001) Human Frontiers, Environments and Disease. Past Patterns and Uncertain Futures. Cambridge University Press.

Manghi, S. (2004) La conoscenza ecologica. Milán, Cortina.

Maturana, H. y Varela, F. (1980) Autopoiesis and Cognitions. The realization of the living. Dordrecht, D. Reidel.

- (1987) The Tree of Knowledge. Boston, Shambhala.

Mèııch, J. C. (2006) Transformaciones. Tres ensayos de filosofía de la educación. Buenos Aires, Miño y Dávila.

- (2008) Antropología narrativa y educación. Teoría de la Educación, 20, 101-124.

Morin, E. (1984) Ciencia con consciencia. Barcelona, Anthropos.

- (2000) La mente bien ordenada. Barcelona, Seix Barral.

- (2006a) El Método III. El conocimiento del conocimiento. Madrid, Cátedra.

- (2006b) El Método VI. Ética. Madrid, Cátedra.

- (2007) Los siete saberes necesarios para la educación del futuro. Barcelona, Paidós.

Morin, E.; Ciurana, E. R. y MotTA, R. D. (2003) Educar en la era planetaria. Barcelona, Gedisa.

Nóvoa, A. (2001) Texts, Images and Memories. Writing "New" Histories of Education, en Popkewitz, T. S.; Franklin, B. M. y Pereyra, M. A. (eds.) Cultural History and Education. Critical Essay on Knolwdge and Schooling. Nueva York, Routledge Falmer, 45-66.

PanikKar, R. (2006) Emanciparse de la ciencia, en Lanceros, P. y Ortiz-Osés, A. (coords.), La interpretación del mundo: cuestiones para el Tercer Milenio. Barcelona, Anthropos, 53-76.

Ponteconvo, C. (1993) Interazione sociale e conoscenza. Le discipline como pratiche di discorso. Scuola e Città, 2.

Pulvirenti, F. (2004) Responsabilità e Formazione. Epistemologie personali in rete di incontro: Bateson, Lipman, Novak. Pisa, ETS.

Righetti, M. (2006) Formazione etica di una scienza per l'uomo, en Gramigna, A.; Righetti, M. y Ravaglia, A. Le scienze dell'innovazione. Nuove frontiere educative nel sociale. Milán, Angeli, 13-50.

Russell, B. (1958) El impacto de la ciencia en la sociedad. Madrid, Aguilar.

Santos Rego, M. A. (2001) Pedagogía holística y gestión de la complejidad en educación. Revista de Educación, 325, 219-233.

Shiva, V. (2008) Los monocultivos de la mente. Madrid, Editorial Fineo.

Sola, G. (2002) Epistemologia Pedagogica. Bergamo, Bompiani.

Steiner, G. (2007) Nostalgia del absoluto. Madrid, Siruela.

Varela, F. (1992) Haciendo camino al andar, en Thompson, W. I. (ed.) Gaia. Implicaciones de la nueva biología. Barcelona, Kairós, 47-62.

Velilla, M. A. (comp.) (2002) Manual de iniciación pedagógica al pensamiento complejo. Bogotá, Instituto Colombiano de Fomento de la Educación Superior y UNESCO. 